\title{
Sobre Susan Sontag: a fotografia como pensamento engajado
}

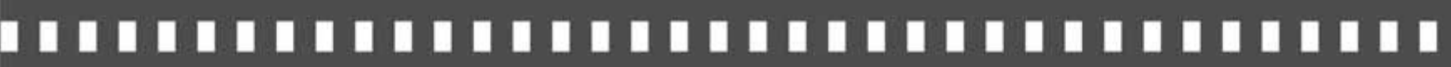

\author{
Susana Dobal
}

Artigo recebido em: 29/06/2016

Artigo aprovado em: 12/09/2017 


\title{
Sobre Susan Sontag: a fotografia como pensamento engajado*
}

\author{
0n Susan Sontag: photography as engaged thinking
}

\begin{abstract}
Susana Dobal ${ }^{\text {** }}$
Resumo: Sobre a fotografia foi escrito no final dos anos 1970 e se tornou um texto clássico na área. Susan Sontag retornaria à fotografia em toda a sua vida intelectual, em outros textos. Ela adotou uma perspectiva que, ao mesmo tempo, era fiel às suas preocupações originais e aprofundava aspectos encontrados em outros autores e temas para os quais ela também dedicou seus escritos. Este artigo investiga, assim, como Sontag usou a fotografia como uma frente para seu engajamento com o desenvolvimento da consciência.
\end{abstract}

Palavras-chave: Susan Sontag. Fotografia. Consciência. Engajamento.

\begin{abstract}
On Photography was written at the end of the 1970s and became a classic text in the field. Susan Sontag would return to photography throughout her intellectual life in other texts. She adopted then a perspective that at the same time was true to her original concerns and deepened aspects found in other authors and themes to whom she also dedicated her writings. This article investigates, thus, how Sontag used photography
\end{abstract}

\footnotetext{
*A produção desse artigo teve o apoio do SESC-SP. Uma primeira versão dele foi apresentada no ciclo de palestras E agora fotografia? Diálogos sobre a pesquisa em fotografia no Brasil.

**Professora na Universidade de Brasília.Fez mestrado em fotografia (International Center of Photography/New York University) doutorado em História da Arte (CUNY/GC), pós-doc na Université Paris 8 e Aix-Marseille Université. Participou de mais de trinta exposições de fotografia. Publicou artigos sobre fotografia, cinema, arte e o livro Peter Greenaway and the Baroque: writing puzzles with images (Berlin, LAP, 2010). Com Osmar Gonçalves, organizou o livro Fotografia Contemporânea: fronteiras e transgressões (Brasília, Casa das Musas, 2013). Desenvolve um blog dedicado a narrativas fotográficas: fotoescritas.blogspot.com
} 
as one front for her engagement to develop conscience.

Key words: Susan Sontag. Photography. Conscience. Engagement.

Quando em 1977 Susan Sontag concedeu uma entrevista por ocasião do lançamento do seu livro Sobre a Fotografia, ela comentou que se deu conta de que escrever sobre esse assunto era na verdade uma forma de escrever sobre a modernidade, acessar maneiras contemporâneas de pensar e sentir. Escrever sobre a fotografia seria então, para ela, uma forma de escrever sobre o mundo. ${ }^{1}$ Tal atitude ajuda a explicar tanto o porquê de seu livro poder soar hoje como datado, quanto o porquê de ele ainda dever ser resgatado. Além de um clássico do pensamento sobre a fotografia, esse livro encontra a sua legitimidade na coerência de um percurso intelectual em que a reflexão foi colocada a serviço do engajamento com uma causa maior em que a imagem fotográfica é apenas uma das peças no tabuleiro.

O livro pode soar datado porque estar no mundo é uma ideia genérica demais, quando os estudos sobre a fotografia nas décadas seguintes tornaram-se mais especializados, concentrando-se nas especificidades de práticas fotográficas diversas, em correntes estéticas, em conceitos que pudessem esclarecer tendências históricas ou ainda em trabalhos específicos de alguns fotógrafos e artistas. Sobre a fotografia, que a autora orgulhosamente defendia como sendo sobre o mundo, tornou-se uma obra aparentemente genérica e superficial, com alguns inegáveis insights sobre a fotografia enquanto prática socio-cultural e com o mérito de um certo pioneirismo em considerá-la como assunto digno de algum aprofundamento, ainda que o tempo o revelasse como insuficiente.

1"In fact, I came to realize that I wasn't writing about photography so much as I was writing about modernity, about the way we are now. The subject of photography is a form of access to contemporary ways of feeling and thinking. And writing about photography is like writing about the world." (SIMMONS, 1977). 
Por outro lado, é justamente esse estar no mundo que surpreende ao longo da obra da escritora, sobretudo nos escritos posteriores sobre a fotografia onde isso iria tornar-se algo ainda mais intenso e evidente. Para Susan Sontag, o exercício de compreensão da fotografia conduz não a uma concepção coerente de tendências ao longo da história da fotografia, mas a uma percepção de como a imagem fotográfica terminar por configurar posicionamentos e concepções do mundo.

A fotografia foi, na obra de Susan Sontag, um dos assuntos aos quais ela se dedicou. A autora escreveu principalmente sobre a literatura mas também sobre temas diversos como o cinema, o Camp, a pornografia, conflitos em países distantes como o Vietnã, tornado próximo pelo envolvimento dos Estados Unidos na guerra, e Sarajevo, ambos países para os quais ela viajou produzindo livros e artigos sobre os mesmos. Duas questões principais permeiam os escritos de Sontag: a estética e a moral. A fotografia será um tema importante na sua obra pois não só permitirá muitas vezes a combinação dessas duas perspectivas como será eventualmente o reflexo do que a autora via em alguns dos autores estudados.

A estética, para Susan Sontag, não se resumia à expressão da beleza, ou pelo menos não de um belo convencional. Já em Sobre a Fotografia ela evocava a maneira como o poeta Walt Whitman nivelava o belo e o feio, o importante e o banal, para associá-lo com as fotografias de Walker Evans, despojadas do heroísmo do poeta porém igualmente empenhadas em decifrar os Estados Unidos e em perpetuar o gesto de encontrar o belo em assuntos, situações e objetos inusitados. Em artigo de quase três décadas depois, Uma discussão sobre a beleza (SONTAG, 2008), a autora comenta o quanto a beleza em si ficou associada a algo conservador e pretensioso, fazendo com que as obras de arte passassem a ser apreciadas não por serem belas, mas por serem "interessantes". A fotografia teria sido a primeira arte em que o interessante triunfou fazendo com que aquilo que antes não era reconhecido como belo fosse enfim percebido como tal (SONTAG, 2008, p. 24). Essa 
capacidade de reconhecer o belo no trivial tornaria a fotografia, segundo a autora, mais contemporânea do que a poesia ou a pintura. O belo trivial visto pelo olhar fotográfico está associado ao "sentido da pura amplitude e plenitude da realidade, inanimada mas também pulsante, que rodeia todos nós" (SONTAG, 2008, p. 29). A fotografia surge então, aqui, como uma maneira de detectar uma realidade plena e pulsante " ela aparecerá de maneira mais ambígua e concreta em outros dos seus escritos, porém, destacase aqui a capacidade da fotografia de eleger o que pode suscitar algum maravilhamento, mesmo que diante da banalidade. Talvez tenha sido pensando nisso que, em texto curto escrito em aforismas, "Fotografia: uma pequena suma", originalmente publicado em 2003, Sontag comenta que "a câmera empurra para adiante as fronteiras do real" (SONTAG, 2008, p. 138). Sontag verá essas fronteiras de maneira menos triunfante e mais crítica em outros textos contemporâneos a esse, porém, há um quê whitmaniano nesse entusiasmo quase incontido que deixa transparecer discretamente um certo fascínio pela fotografia - apenas discretamente, porque do contrário, pareceria um élan ingênuo.

Susan Sontag atribui à fotografia algumas características que ela detecta também nos autores a quem dedicou ensaios. Assim, se a fotografia aparece em um dos aforismas de 2003 como a maneira inelutavelmente moderna de ver, baseada em fragmentos, longe de ideias unificadoras e sem negar a "infinita variedade e complexidade do real" (SONTAG, 2003, p. 137), logo isso remete ao Walter Benjamin do seu artigo "Sob o Signo de Saturno"(SONTAG, 1986b). Sontag comenta que Benjamin se projeta nos autores sobre quem escreveu como Kafka, Baudelaire e Proust. Ela, por sua vez, destaca em Benjamin a sua afinidade por fragmentos, aforismas, coleções, mecanismos de transformação de coisas em alegorias típicos do temperamento contemplativo do autor saturnino, ou ainda a afinidade dele pelas ruínas - ou seja, muitos dos mesmos mecanismos que ela reconhece nas suas afirmativas genéricas sobre a maneira como a fotografia funciona. Nos 
aforismas sobre a fotografia, por exemplo, ${ }^{2}$ Sontag a vê como uma maneira de colecionar fragmentos em uma espécie de acumulação sem fim - uma visão bem ao gosto da sensibilidade barroca sobre a qual Benjamin escreveu a sua tese de livre-docência que tratava do drama barroco. O fato de Sontag mostrar-se tantas vezes tão engajada no seu papel de ativista não a impede de comentar em um artigo sobre a atração que ela também tinha pelas ruínas. $\mathrm{O}$ artigo se chama, não por acaso, "O Prazer da Imagem" (SONTAG, 2002b, p. 142-150), originalmente publicado na revista Art in America, em 1987) e trata de uma certa ambiguidade em relação às ruínas e à nostalgia que lhe é atribuída.

Caminhando por uma coleção de pinturas holandesas, ela desvia sua atenção para pintores menos conhecidos do século XVII (coincidência ou não, do período barroco) e admira neles a representação de vastos espaços: "Aquela sensação fugaz de estar fora-do-corpo e dentro-do-quadro, que alcanço ao investigar a representação desses espaços vastos povoados de criaturas pequenas, ao longo de décadas de visitas a museus, provou ser viciante". ${ }^{3}$ Ela mal resiste à própria diluição no espaço representado nas pinturas; já Benjamin, sob o signo de Saturno, gosta de se perder nas cidades mas associa conhecer a mapear e trabalha preferencialmente com espacializações, como por exemplo, as ideias e as experiências vistas como ruínas. Sontag detém-se diante de um quadro que representa o interior de uma igreja, admira a majestade da arquitetura nos quadros e confessa se sentir atraída pela representação dos espaços melancólicos da arquitetura italiana. Mas o prazer da imagem que dá o título ao artigo vem de observar um mundo onde "transgredir não é uma ameaça" e a "nostalgia não é uma compulsão". Tal mundo se configura em um dos quadros em que, apesar da

2 Susan Sontag, "Fotografia: uma pequena suma". (SONTAG, 2008. p. 137140).

3 "And that flicker of an out-of-body, into-the-picture sensation I'm granted in the course of scrutinizing the renderings of these large, impersonal spaces populated with very small figures has proved, over decades of museum-going, to be addictive" (SONTAG, 2002b, p. 142). 
solenidade da igreja, pessoas passeiam tranquilamente por ela, sem necessariamente estarem envolvidas com a fé implícita ao ambiente e como se para confirmar tal deslocamento, um cachorro faz xixi em uma das colunas do interior da igreja representado no quadro. A atitude do cachorro tem outros ecos na obra de Susan Sontag: talvez paradoxalmente ela traduza o caráter moral de muitos dos seus escritos e também o papel da própria fotografia, muitas vezes vista como enganadora, mas também fascinantemente atrelada à realidade. Ao contrário de Benjamin, em quem ela identifica a atração pela destruição e pela ruína, ela preza as imagens em que a nostalgia não é uma compulsão, ou seja, ela não se permite sucumbir ao magnetismo das ruínas. Um dos momentos em que isso fica mais aparente é no seu ensaio sobre a imaginação pornográfica. ${ }^{4}$ Embora ela trate principalmente da imaginação literária, os argumentos que a autora usa para redimir a pornografia oferecem pistas para que se compreenda qual papel ela vai atribuir à fotografia quando do seu retorno ao assunto três décadas depois do seu livro pioneiro.

$\mathrm{O}$ artigo sobre a imaginação pornográfica é motivado pelo fato de que a pornografia, em geral, não seria considerada literatura e isso se deveria a ideias equivocadas tanto sobre a literatura como sobre a pornografia. A primeira estaria presa a definições limitadas que a relacionam ao realismo, à construção de personagens em termos sociológicos e psicológicos quando ideias e coisas inanimadas também seriam temas legítimos pois o que contaria para a literatura, em última instância, é como o mundo se constitui pela consciência. Sendo assim, estados extremos de sentimentos e consciência, separados da vida cotidiana, como é o caso da pornografia, também seriam temas válidos para a literatura - a autora refuta ou pelo menos relativiza o fato de a literatura pornográfica ser desprovida de densidade, ou povoada de personagens deliberadamente rasos em termos psicológicos. Para ela, a pornografia só se tornou assimilável quando, na Europa, a definição de literatura acatou formas extremas de consciência que transcendem a personalidade 4 Susan Sontag, "The Pornographic Imagination" (1967) in Styles of Radical Will. New York, Picador, (SONTAG, 2002, p. 35-73). 
social ou a individualidade psicológica. A pornografia, por outro lado, estaria ela também limitada pelo fato de só ser considerada, em geral, como um fenômeno sociológico ou psicológico, como um motivo de preocupação em termos sociais e não como uma obra de arte.

Sontag passa a analisar e comparar algumas obras clássicas da literatura pornográfica (como os livros de Sade de uma maneira geral e especialmente Os Infortúnios da Virtude; História de O, de Pauline Réage (pseudônimo de Anne Desclos); História do Olho e Madame Edwarda de Georges Battaille), a fim de comparar essas obras e demonstrar que a pornografia literária pode sim requisitar o título de obra de arte. Dentre esses autores, Sontag privilegia especialmente Bataille em quem ela identifica um senso mais profundo de transgressão, o domínio da linguagem de maneira mais sofisticada que os outros autores, e a compreensão de que aquilo que o obsceno trata, finalmente, é a gratificação da morte. Sem mencionar o livro O Erotismo, de Bataille, publicado dez anos antes desse artigo, ela também associa a religião à experiência erótica, reconhecendo o vocabulário religioso como único disponível para representar a experiência da imaginação total conhecida pelo artista, pelo erotômano, pelo esquerdista e pelo louco. Ela lamenta que, com a derrocada da religião, a sociedade contemporânea não ofereça nenhuma outra forma de transcender a individualidade: "A necessidade dos seres humanos de transcender "o pessoal" não é menos profunda do que a necessidade de ser uma pessoa, um indivíduo. Mas essa sociedade serve a essa necessidade precariamente." ${ }_{5}$

Sontag compara a Justine, de Sade, à personagem de História de $O$ : enquanto a primeira é sucessivamente humilhada voltando sempre à estaca zero sem nunca aprender nada das suas desventuras, O passa por situações extremas, sofre, transforma-se, mas busca deliberadamente a satisfação pela degradação, mostrando-se

5 "The need of human beings to transcend "the personal" is no less profound than the need to be a person, and individual. But this society serves that need poorly." (SONTAG, 2002a, p.70). 
agradecida por ter sido introduzida no "mistério da perda do eu", oscilando entre a vacuidade uma plenitude comparável à experiência religiosa. O que separa as duas personagens é a consciência, e o que finalmente redime a pornografia é a arte: "Eu defendi que esta forma precária da imaginação humana tem, no entanto, o seu acesso peculiar a alguma verdade. Esta verdade - sobre a sensibilidade, sobre o sexo, sobre a personalidade individual, sobre o desespero, sobre os limites - pode ser compartilhada quando se projeta na arte." "Sontag visita, pela literatura, os rituais da pornografia e da degradação pessoal mas volta com um troféu: a arte. Essa arte tem menos a ver com a beleza do que com a consciência, por isso ela menciona o acesso a uma verdade, ainda que provisória. Esse será o melhor antídoto para a ruína e o artigo conclui denunciando a vida miserável de um erotômano além de se insentar da defesa da pornografia como experiência necessária e assimilável a todos.

Como todo esse discurso sobre a pornografia poderia estar relacionado à fotografia quando ela mesma mal é mencionada naquele artigo? O caminho para se chegar à fotografia na obra de Sontag passa pela firme determinação de evitar a ruína. A destruição e a morte, uma morte em sentido menos figurado, estará subentendida em outros momentos da obra da autora, mas ela deverá ser contornada em nome da sobrevivência não apenas pessoal, mas coletiva. A guerra sempre foi uma preocupação de Sontag definida em geral como escritora, cineasta, e ativista. Em 1968, em plena guerra do Vietnã (1955-1975), ela visita o país com dois outros americanos, um matemático pacifista e um jornalista que ela conhece na ocasião da viagem e quando volta, ela publica um relato dessa experiência no livro Viagem a Hanói - publicado, aliás, no mesmo ano no Brasil. A visita era uma iniciativa dos vietnamitas que já tinham convidado cerca de quarenta americanos antes desse grupo. Eles se ocupavam em receber os americanos

6 "I've urged that this spectacular cramped form of the human imaginagion has, nevertheless, its peculiar access to some truth. This truth - about sensibility, about sex, about individual personality, about despair, about limits - can be shared when it projects itself into art" (SONTAG, 2002a, p. 70-71). 
e fazê-los conhecer o país enquanto os convidados, em geral pacifistas, jornalistas, escritores, pessoas com capacidade de mobilizar consciências, arcavam com os custos da viagem. O livro de Sontag é uma espécie de diário que relata a experiência cotidiana, locais visitados, pessoas com quem se encontraram, diálogos, troca de ideias, e principalmente as hesitações de uma consciência inicialmente desnorteada e assumidamente confusa diante uma cultura tão diferente da sua. A autora se questiona diversas vezes sobre a sua capacidade de decifrar o Vietnã, mas em um momento do livro, prestes a desistir da empreitada, ela atravessa a fronteira cognitiva e nos seus próprios termos consegue deixar de lado a sua maneira ocidental de involuntariamente querer projetar os seus parâmetros para desvendar uma cultura incompatível com as suas expectativas.

Sontag considera essa viagem como um dever, um ato de afirmação pessoal e política, mas fica incomodada ao se perceber como uma personagem em uma peça de teatro e principalmente com o fato de vir de um país que impunha tanta destruição ao Vietnã e ser ainda assim tão bem tratada pelos seus anfitriões. Para sua surpresa, ela recebia muitos presentes e diversos vietnamitas falavam dos Estados Unidos com admiração pelo avanço tecnológico e pela democracia, além de mostrarem interesse em visitar o país quando a guerra terminasse. O que mais a surpreende, no entanto, é a moral dos vietnamitas, tão diferente do mundo ocidental e que fazia, por exemplo com que um soldado americano morto em um avião abatido em território vietnamita recebesse um túmulo ornamentado com flores, peças do avião e nos dizeres de um cidadão local que a levou para visitar aquele túmulo em uma cidade pequena no meio da estrada, com um caixão feito de boa madeira para que assim os pais, quando viessem visitar o filho, pudessem transportar o corpo com segurança. Sontag vê o Vietnan como uma sociedade com valores éticos ampliados, onde as exigências morais comunistas só se difundem porque encontram eco em um prévio "respeito inato vietnamita por uma ordem social e pessoal altamente moralizada" 
(SONTAG, 1968, p. 98). Tratando-se de um convite oficial, essa situação gera um certo desconforto ao leitor pois soa como uma possível encenação. De uma forma ou de outra, ela é retomada aqui para acompanharmos que tipo de preocupação movia a autora.

Ela se defende de estar imbuída do que poderia ser visto como um "sentimentalismo postiço" diante do Vietnã, argumentando que suas conclusões vêm da observação direta dos fatos. $\mathrm{O}$ tratamento dado às milhares de prostitutas que sobraram do período da colonização francesa após a libertação do país, em 1954, parece-lhe um caso sintomático. Elas foram entregues aos cuidados da União das Mulheres que as fizeram passar por um processo de reabilitação que consistia primeiramente em mimálas com histórias maravilhosas e jogos infantis para que, conforme explicação dada a Sontag, restaurassem a fé na humanidade após terem conhecido um aspecto terrível da natureza humana. Em seguida foram alfabetizadas, instruídas para uma atividade profissional e finalmente ganharam um dote para encorajar a possibilidade de um casamento e reinserção na sociedade. Sontag conclui: "Não pode haver dúvida alguma de que um povo capaz de imaginar uma tal terapêutica possui, realmente, uma imaginação moral muito diferente da nossa." (SONTAG, 1968, p. 126).

Além de se basear na observação, Sontag também reconhece as fraquezas da sociedade local, a começar pela retórica oficial incapaz de fazer justiça às qualidades morais dos vietnamitas. Ela também estava ciente das atrocidades cometidas por um governo longe de servir de modelo de justiça, mas defende que o posicionamento vietnamita voltado para a coletividade contrasta com o individualismo ocidental. Assim como ocorre no caso de muitos dos escritores sobre quem Sontag tratou nos seus ensaios, a solidariedade como prerrogativa reconhecida nos vietnamitas parece estar refletida na própria escritora quando ela, ao falar do seu patriotismo, argumenta que acima do amor pelo seu país estariam os interesses da humanidade. Com esse mesmo posicionamento ela viajaria décadas mais tarde para a região conflituosa da Guerra 
da Bósnia com o propósito similar de se interar sobre o conflito e ajudar a mobilizar consciências. Em Sarajevo, na cidade sitiada, em 1993, ela dirigiu uma montagem de Esperando Godot, de Samuel Beckett. Embora tenha tido uma receptividade ambígua na época, a montagem terminou ganhando notoriedade com o tempo. Em reconhecimento pela divulgação que ela deu ao conflito coberto pela imprensa internacional também por causa da encenação da peça, além do artigo sobre o conflito e a sua montagem da peça que na época ela publica no jornal The Observer, as autoridades locais renomearam a praça onde a peça foi encenada com o nome da escritora. Esperar por Godot era então uma referência à espera por uma atitude dos Estados Unidos e da ONU para intervir na cidade ameaçada pelo poder sérvio.

O sentido da moral, uma preocupação subjacente nas suas observações sobre Hanói, permeia a maior parte da obra de Susan Sontag e emerge progressivamente nos seus escritos sobre a fotografia. Se o livro da década de 1970, tendia mais para uma preocupação com a estética fotográfica, a moral vai dominar os seus escritos mais recentes sobre esse tema. A moral, para ela, não se resume a um conjunto de regras que restringem o comportamento de cada um em nome do bem comum, embora essa dimensão não esteja ausente. A moral se aproxima da ética e se manifesta por um compromisso com a justiça expresso no engajamento para afastar a destruição, evitar a ruína no plano coletivo - o que não a impediria de incentivar a transgressão de si e denunciar toda forma de coerção que a impeça. ${ }^{7}$ Sontag sempre vai oscilar entre esses dois extremos. Em Sobre a Fotografia ela comentava o grande impacto que lhe causou quando em 1945, pela primeira vez, aos doze anos, viu em uma livraria, as fotos dos campos de concentração de Dachau e Bergen-Bessen: "algo morreu, algo ainda chora" (SONTAG, 1986a,

7 Ver nota 3 ou ainda, dito de outra forma na entrevista para a Rolling Stone: “Eu acho que devemos permitir não apenas estados de consciência e pessoas marginais mas também o incomum e o depravado. Sou a favor dos depravados." ("I think we have to allow not only for marginal people and states of consciousness but also for the unusual or the deviant. I'm all for deviants." (COTT, 2013, p. 31). 
p. 28). ${ }^{8} \mathrm{O}$ impacto dessa visão irá transparecer em muitos dos seus escritos na vida adulta. Por outro lado, na longa entrevista cedida a Jonathan Cott publicada parcialmente na revista Rolling Stone e depois integralmente em livro, ela comenta que sua vida mudou uma outra vez também por influência de um estímulo externo, mas por razões menos trágicas. Respondendo ao refrão de música de Bill Halley proposto pelo entrevistador quando o diálogo versava sobre seu duplo interesse, inusitado nos anos 50 (seus anos de aluna universitária), pela música erudita e pela música pop, ela ri e comenta:

Não eram as palavras, era a música. Eu posso dizer abertamente: escutei um som dionisíaco e como n'As Bacantes, eu me levantei e quis seguir. Quer dizer, eu não sabia o que eu queria - não é que eu fosse sair e me juntar a uma banda - mas eu sabia que era como a última linha do famoso poema de Rilke [Torso Arcaico de Apolo]: "Força é mudares de vida". E eu sabia disso, visceralmente. ${ }^{9}$

Portanto, por um lado, há o impacto das imagens dos campos

8 Em outra entrevista, Sontag comenta mais sobre esse acontecimento: "I think that that experience was perhaps only possible at that time, or a few years after. Today that sort of material impinges on people very early. [...] That was before television, and when newspapers would print only very discreet photographs. [...] It made me sad in a way that I still feel sad. It wasn't really the end of childhood, but it was the end of a lot of things. It changed my consciousness. I can still remember where I was standing and where on the shelf I found that book." in Charlie Simmons (SIMMONS, 1977).

9 "It wasn't the words, it was the music. I put it very plainly: I heard a Dionysian sound, and just as in the The Bacchae, I stood up and wanted to follow. I mean, I didn't know what I wanted to do I wasn't going to go out and join a band - but I knew that it was like the last line in the famous Rilke poem ["Archaic Torso of Apollo"]: 'You must change your life.' And I knew it viscerally "(COTT, 2013, p. 36). O verso em português de Rilke foi pescado da tradução do poema por Manoel Bandeira, disponível no blog do Antônio Cícero: antoniocicero.blogspot. com.br/2010/12/rainer-maria-rilke-archaischer-torso.html Adoto essa versão menos informal do que a fala em inglês da entrevistada porque ele parece ter uma maior afinidade com o ardor do poema e com o que Sontag se refere na entrevista, mesmo que o original diga apenas: Du mußt dein Leben ändern. 
de concentração que ressoaria mais adiante na vida da escritora como um ultraje que detona a retidão de um compromisso. Por outro lado, há o desassossego das tentações seja pela melodia sedutora do rock, seja pelas aventuras mais arriscadas que a levariam a viajar rumo a conflitos no Vietnã (1968), em Israel (Guerra do Yom Kippur, 1973), na Bósnia (1993), ou ainda a pontuar o seu textos com um verbo recorrente que, aqui e ali, vemos pipocar: to trespass/ transgredir. Seu envolvimento com a fotografia seria marcado por uma ambiguidade parecida: por um lado havia o apelo moral para reagir diante de situações que lhe pareciam injustas; por outro lado, havia um envolvimento literalmente passional se pensarmos no seu relacionamento de mais de quinze anos com a fotógrafa Annie Leibovitz que durou até a morte de Sontag em 2004, mas para além da vida pessoal, um envolvimento também passional no sentido de que a fotografia permeia seus escritos ao longo de diferentes momentos da sua vida e serve de ponte para ela se conectar com o mundo concreto.

Regarding the pain of others, em português, Diante da dor dos outros, livro publicado um ano antes da sua morte, trata da fotografia de conflitos retraçando representações históricas da guerra a começar pelas gravuras, até a fotografia mais recente. Interessam-lhe os mecanismos de construção histórica pelas imagens que sempre terminam por demonstrar menos os conflitos em si do que posicionamentos diante deles, além de determinar quais conflitos restarão na lembrança. Ela não poupa a fotografia das repetidas montagens que forjaram a representação de certos conflitos desde o começo da sua história. A surpresa maior, ela comenta, não é com essas encenações, mas com o fato de que alguém ainda possa se desapontar com elas. Sontag lamenta ainda que lembrar seja cada vez mais uma questão de recordar-se apenas de uma foto e não de um contexto maior (SONTAG, 2003, p. 89). As narrativas parecem-lhe mais efetivas do que a fotografia (SONTAG, 2003, p. 122) porque as imagens não escapam de ser apenas relatos parciais dos acontecimentos. Ainda assim, ela faz a 
ressalva de que uma pintura evoca, enquanto uma fotografia é uma evidência de que algo efetivamente ocorreu. Por meio de fotografias mencionadas, e jamais mostradas, Sontag denuncia o caráter injusto das representações de conflitos ou o voyeurismo implícito diante da dor alheia especialmente quando se trata de conflitos distantes, ao mesmo tempo em que ela também reconhece o poder evocatório da fotografia ao tornar real conflitos que seriam ignorados. Ou seja, ciente das ambiguidades inerentes à imagem, ela trata a fotografia menos como um documento histórico do que como um artifício no tabuleiro político.

Muito do que se apresenta em Diante da dor dos outros voltará de forma mais intensa no seu artigo sobre as fotos dos prisioneiros de Abu Graib tiradas pelos soldados do exército norteamericano, cujo título, "Diante da tortura dos outros", faz referência direta ao livro. ${ }^{10}$ As fotos dos prisioneiros nus ou encapuzados foram amplamente divulgadas na época em que foram feitas. Elas mostram cenas de tortura e a repercussão que tiveram se deve não só à tortura em si, mas também porque os soldados se fotografaram na frente dos prisioneiros, como se a situação fosse apenas um tipo de divertimento do qual se faz fotos alegres para serem difundidas entre os amigos. A total falta de visão dos soldados vira uma afronta cujas raízes são retraçadas no artigo de Sontag. Se em Diante da dor dos outros ela já defendia a força das fotos de amadores na cobertura do atentado de onze de setembro, no artigo ela investiga menos o conteúdo das fotos do que a motivação do gesto de fotografar e a repercussão dele exposta também como um posicionamento infame do governo seja por querer impedir a continuação da difusão das imagens, seja por sequer admitir que se tratasse de tortura e não de uma diversão justificada. Sontag estava de olhos bem abertos e ouvidos atentos: para construir seus argumentos e revelar o absurdo implícito na produção e difusão das fotografias, ela recorre a citações de políticos, de radialistas, convenções sobre a tortura

$10 \mathrm{O}$ artigo escrito para o The New York Times (23.5.2004) foi publicado em 6.6.2004 no jornal Estado de São Paulo e está reproduzido no livro Ao mesmo tempo (SONTAG, 2008). 
das quais os Estados Unidos são signatários, práticas diversas que naturalizam a violência como o trote nas universidades e os video games, ou ainda a prepotência colonial, a pornografia masoquista, o exibicionismo nas redes sociais, todo um cenário que permitia enfim que as fotografias tenham sido produzidas, difundidas e recebidas com uma conivência difusa em diferentes estratos da sociedade norte-americana.

Sua análise aguda das fotografia produzidas na prisão de Abu Graib revelam a escritora falando não do ponto de vista de conhecedora da história da fotografia e das suas motivações estéticas como no seu livro de 1977. Ela agora falava de fotografia de uma posição mais próxima dos seus lúcidos artigos que criticaram a escalada bélica dos Estados Unidos motivados pelos ataques de onze de setembro, artigos e entrevista em que ela denunciava o maniqueísmo e a retórica da política externa do presidente Bush e a pouca disposição dos norte-americanos, em geral, para refletir e debater sobre as motivações dos atentados e uma política eficiente para fazer frente à ameaça. ${ }^{11}$ Ela denuncia ainda o fortalecimento desmedido do Estado sob a justificativa da ameaça iminente - um fato que terminaria por ser confirmado pelas futuras fotos de $\mathrm{Abu}$ Graib. A fotografia desse final da sua vida emerge, portanto, do momento presente, impregnada pela cultura e pela política, trazendo à tona posicionamentos e produzindo ecos, veiculando imagens que funcionam como a moeda corrente.

Sontag, porém, não renunciaria totalmente a uma visão da fotografia como uma categoria mais abstrata. Seu artigo "Fotografia: uma pequena suma" de 2003 (SONTAG, 2008, p. 137-140) foi escrito na forma de aforismas e volta às ideias gerais que também permeiam o livro Sobre a Fotografia. O formato dos aforismas é usado, porém, justamente para comentar o caráter fragmentário da fotografia que a tornaria tão contemporânea e avessa às ideias unificadoras. Esses fragmentos de imagem não negam a "infinita variedade e complexidade do real" e trazem a sensação de que "a 11 Para esses artigos e entrevista ver "11/9/2001", "Algumas semanas depois" e "Um ano depois". (SONTAG, 2008). 
realidade é essencialmente ilimitada e o conhecimento não tem fim" (SONTAG, 2008, p. 137-138). O olhar crítico e indignado cede aqui àquele entusiasmo com a fotografia reconhecível em diferentes momentos da sua obra. Assim, uma vez desvelados todos os enganos a que a fotografia pode conduzir, Sontag ainda atribui a ela o papel de levar a novas descobertas: “O que é liberador, assim nos dizem [as fotografias], é perceber cada vez mais" (SONTAG, 2008, p. 138).

Perceber cada vez mais poderia ter sido o mote que uniu Susan Sontag à fotógrafa Annie Leibovitz nos últimos quinze anos da sua vida, consolidando o seu elo com a fotografia também em um plano pessoal. Leibovitz comentou diversas vezes como Sontag a incentivava, tendo sido quem teve a ideia do livro Women para o qual ela escreveu um texto introdutório. $\mathrm{O}$ incentivo era recíproco, pois a fotógrafa apoiava Sontag financeiramente para que ela pudesse dar menos palestras e escrever. A famosa fotógrafa de celebridades tem as suas fotos editadas de forma a que uma coleção de vistosos retratos se transforme em um gesto político. Sontag comenta no texto que as mulheres são uma minoria cultural, uma obra em andamento pois sempre têm que se afirmar a partir de um ponto de partida dado como em princípio precário se o critério não é a beleza, qualidade impensável para uma coleção de retratos masculinos. Seu texto faz comparações sobre a representação da mulher e do homem e das expectativas diferentes de representação de um e de outro. Enquanto espera-se da mulher placidez, beleza e subserviência, espera-se do homem altivez, coragem e determinação. O objetivo do livro, que traz retratos de mulheres nas mais diversas profissões, da costureira à diretora de empresa passando pela atriz, a dançarina, a juíza, a cientista, a jornalista, a garçonete, a astronauta etc, é demonstrar que as atribuições profissionais divididas por gêneros tornaram-se se não obsoletas pelo menos enfraquecidas nos Estados Unidos, mesmo com a ressalva de que os salários ainda são diferentes ainda que as atividades muitas vezes sejam as mesmas. Essa galeria de mulheres, essa categoria a quem foi impingido a obrigação da 
beleza, traz personagens nem sempre belas e termina por ilustrar bem aquela ideia de Sontag sobre o caráter democrático do belo fotográfico que elege assuntos comuns para serem enquadrados.

Apesar de as fotos terem sido feitas por Leibovitz, é difícil pensar que elas teriam aparecido nesse formato, reunidas em série e ressignificadas para além de pautas de trabalhos dispersos, se não fosse pela influência de Sontag. Na obra de Leibovitz, em geral, transparece mais nos seus retratos um glamour lucrativo pois pouco convencional, do que um engajamento estético. Desse encontro, portanto, emerge também um sentido da fotografia que é próprio da maneira como Sontag a queria enxergar, isto é, como um veículo, ainda que por vezes enganador e ambíguo, para fazer ver a realidade, e se preciso, defender ideias.

A maior paixão de Sontag, no entanto, foi pelo conhecimento, pelo ato de pensar e não pairar apenas na superficialidade do mundo. Essa paixão não era exclusivista, ela precisava de artifícios que a fizessem florescer: a fotografia foi um deles. Sontag colocou-se em posição privilegiada para analisar isso que parece ser apenas um exercício de apreensão de superficialidades, de meras aparências fugazes e pouco confiáveis nem por isso menos fascinantes. Ao tratar da fotografia, ela não vai se ater a aparências, irá atrás das raízes que expliquem a sua inserção no mundo. Talvez por isso encontramos nos seus livros uma ausência que parece ser uma contradição: nos seus muitos escritos publicados sobre a fotografia não vemos jamais uma imagem. O que finalmente sempre a interessou eram as ideias por detrás das imagens. Ou seja, as palavras. Por esse motivo oscilava entre um genuíno interesse pela fotografia que permeia toda a sua vida e uma também genuína desconfiança da sua superficialidade. Dessa forma ela denuncia, por exemplo, o sentimentalismo humanista e o limite do conhecimento fotográfico em Sobre a fotografia: "embora possa despertar consciências, [a fotografia] nunca pode ser um conhecimento ético ou político" (SONTAG, 1986a, p. 31).

Leibovitz fez inúmeros retratos de Susan Sontag, muitos 
deles publicados na sua antologia A Photographer's Life: 19902005, inclusive uma imagem de Sontag morta. Mas Sontag sempre foi refratária a falar da sua vida pessoal, mesmo que Leibovitz tenha declarado que ela certamente a teria apoiado também nessa publicação. No artigo sobre Walter Benjamin, Sontag começa comentando uma série de retratos do autor, eles são descritos, mas jamais mostrados. Para que serviria uma imagem? Aqui ela não parece seduzida pelo poder da fotografia de, como um carimbo, imprimir lembranças; o verdadeiro retrato estava no ensaio escrito que procura decifrar a sensibilidade do autor. Assumindo, portanto, a insuficiência inerente a um retrato, esse artigo chega ao final com uma foto de Annie Leibovitz em que Sontag estava presente, mas não foi enquadrada.

As duas estavam em Sarajevo, onde tinham ido por ocasião dos interesses que Sontag tinha no país durante a Guerra da Bósnia. Leibovitz comenta que não teria ido lá se não fosse por conhecer Sontag. Uma arma é disparada perto do carro delas enquanto passavam atingindo um garoto em uma bicicleta. Elas levam o garoto até o hospital mas ele não resiste e morre. A foto mostra apenas a bicicleta no chão e a pincelada curva de sangue que o corpo deixou no asfalto. ${ }^{12}$ Nada é realmente mostrado, e sim apenas sugerido. Há uma beleza infame no movimento implícito da bicicleta caída e do rastro pincelado no chão: a beleza vem da mancha de sangue que mais parece o gesto do pincel que escreve um ideograma; a infâmia vem do fato que alguém tão jovem morreu por força quase do acaso e para sintetizar o horror da guerra com uma caligrafia trágica. Ao comentar as circunstâncias dessa fotografia, Leibovitz diz que o tiro veio de um morteiro, mas o título refere-se a um franco-atirador. A discrepância incomoda Martin Bayer (2009), autor de uma crítica sobre a exposição retrospectiva da fotógrafa em uma galeria em Berlin. Ele comenta que a mudança do relato oral para o oficial parece ter o intuito de aumentar a dramaticidade da imagem, e para corroborar sua revolta, ele acrescenta um trecho em 12 A fotografia de Annie Leibovitz pode ser vista no artigo de Martin Bayer sobre uma exposição da fotógrafa publicada em Bayer (2009). 
que Annie Leibovitz comenta que não é fotojornalista e por isso seu compromisso com a objetividade é relativo. A ambiguidade sobre a origem do tiro que causou a morte do garoto e a caligrafia no chão é coerente com a imprecisão geralmente atribuída à fotografia nos textos de Susan Sontag, assim como o próprio assunto, a morte em um conflito bélico, ou mais do que isso, um libelo contra a morte vã em uma guerra. Afinal, o que sempre subjaz nos textos de Sontag de maneira mais ou menos explícita é o que ela resgata nos escritos de Cioran, mais um autor sobre quem ela escreveu em artigo que também traz pistas sobre a sua compreensão da fotografia, mesmo sendo um assunto totalmente alheio a ele. ${ }^{13}$

Cioran é situado em um momento em que a filosofia perdeu a credibilidade como capaz de oferecer modelos formais para a compreensão de algo, o que dá lugar ao surgimento de ideologias e a novas formas de filosofar mais pessoais, aforísticas, antisistemáticas - que melhor definição para os próprios textos de Sontag? Cioran aparece assim ao lado de Kierkegaard, Nietzsche e Wittgenstein, embora guarde as suas especificidades que ela desenvolve no ensaio. Para falar de Cioran, Sontag comenta principalmente as grandes afinidades e mais sutis diferenças entre ele e Nietzsche, seu mestre implícito, mas conclui o seu texto em outra comparação com os escritos de John Cage para finalmente identificar no pessimismo de Cioran uma inusitada especificidade: em contraste com o papel do acaso e a postura leniente de John Cage, Cioran privilegia o papel da vontade e a sua capacidade de transformar o mundo. Não parece por acaso que ela tenha escolhido o filósofo como tema de mais um dos seus ensaios.

A foto da bicicleta que derrapou deixando a marca de sangue no chão muda de sentido ao longo do tempo: o documento de uma guerra específica cede aos poucos ao libelo contra todas as guerras. $\mathrm{O}$ engajamento que emerge dos textos de Sontag em geral, e também especificamente nos textos sobre a fotografia $13 \mathrm{O}$ artigo 'Thinking Against Oneself': Reflections on Cioran" foi publicado em Sontag (2002a, p. 74-95) e pode ser encontrado também em: https://emcioranbr. wordpress.com/fortuna-criativa/thinking-against-oneself/ 
posteriores ao seu clássico On Photography, pode parecer datado. Suas viagens rumo a conflitos mundo afora faz lembrar a obra de Eugene Smith, por exemplo, o fato de ele ter se casado novamente e partido na lua-de-mel para fazer uma longa cobertura sobre o envenamento por mercúrio em uma aldeia de pescadores no Japão. Dentro de uma tradição humanista, cada um a seu modo, Smith e Sontag pensam e usam a fotografia como uma forma de mudar o mundo. A tradição que vai imperar depois da primeira metade do século XX seria menos otimista, mais desesperançada, embora não se perca a vontade de fazer denúncias em muitas das produções da fotografia documental. No entanto, não seria esse um vigor ainda necessário? Afinal, Sontag finaliza o texto de introdução ao livro Women de Leibovitz, texto em que defende as fotografias como forma de necessária afirmação do valor social das mulheres, com as seguintes frases:

"Cabe a nós decidir o que fazer dessas fotos. Afinal, a fotografia não é uma opinião. Ou é?" ${ }^{14}$ Muito é dito em cada verbo desse trecho: "cabe a nós decidir", como se fosse sempre uma questão de decisão e não apenas de assimilação das palavras e das imagens; "o que fazer", porque as fotografias seriam uma proposta, uma provocação; "a fotografia não é uma opinião", ou seja, ela teria um certo coeficiente de verdade afinal aquelas mulheres naquelas profissões, mesmo que filtradas pelo peso da cultura, realmente existem; e por fim ela faz uma indagação retórica deixando a suposição de que a fotografia é sim uma opinião, uma afirmativa, um fragmento que, olhando retrospectivamente para os seus escritos, deve levar à ação. Susan Sontag não tirava fotografias, mas a maneira como ela se manifesta por algumas das fotos de Annie Leibovitz, assim como a maneira como ela falou de tantos autores, deixa transparecer uma concepção da fotografia que vacila entre o engajamento e aforismas que procuram abstrair seus mecanismos de uma maneira menos circunstancial. Não seria essa estratégia mesma da fotografia documental: reagir a uma realidade que se 14 "It's for us to decide what to make of these pictures. After all, a photograph is not an opinion. Or is it?"(LEIBOVITZ, 1999. p. 36). 
apresenta à frente e abstrair para representar a melhor versão dela? Os escritos de Susan Sontag sobre a fotografia oscilaram entre dois pólos: comentar obras específicas e identificar mecanismos mais genéricos que explicassem a fotografia como um posicionamento no mundo por meio de imagens. A balança começou pesando mais para o lado da estética e, na contra-corrente do pensamento sobre a fotografia, terminou indo para o lado da ação e do engajamento - esse seria para ela a sua percepção da Moral necessária, o objetivo último do comportamento e das atitudes. Mas, enfim, seu engajamento último foi com a consciência (Cioran é descrito como um voyeur da própria consciência tal qual transparece em muitos dos textos de Sontag) e para isso ela sempre se colocou favorável às transgressões, a um distanciamento que permita não só ver além como também posicionar-se. Cabe a nós decidir o que fazer desses escritos afinal a fotografia é um grito solto no mundo. Ou não?

\section{Referências}

BAYER, Martin. Annie Leibovitz: “a photographer's life. 1990-2005. 2009. Disponível em: <http://www.wartist.org/ blog/?p=379\&lang=en>. Acesso em: 28 jun. 2016.

COTT, Jonathan. Susan Sontag: the complete rolling stone interview. London: Yale University Press, 2013.

LEIBOVITZ, Annie. Women. New York: Random House, 1999.

SIMMONS, Charles. Sontag talking. New York Times, New York, 18 Dec. 1977. 
SONTAG, Susan. Ao mesmo tempo: ensaios e discursos. São Paulo: Cia das Letras, 2008.

SONTAG, Susan. Ensaios sobre a fotografia. Lisboa: Publicações Dom Quixote, 1986a.

SONTAG, Susan. Regarding the pain of others. New York: Farrar, Straus and Giroux, 2003.

SONTAG, Susan. Sob o signo de saturno. São Paulo: L \& PM, 1986b.

SONTAG, Susan. Styles of radical will. New York: Picador, 2002a.

SONTAG, Susan. Viagem a Hanói. Rio de Janeiro: Expressão e Cultura, 1968.

SONTAG, Susan. Where the stress falls. New York: Picador, $2002 b$. 